\title{
The Prediction and Optimization of the Effects of Abrasive Waterjet Cutting Parameters On Kerf
}

\begin{abstract}
M. $\mathrm{AY}^{a *}$ AND İ. $\mathrm{AY}^{b}$
${ }^{a}$ Marmara University, Faculty of Technology, Department of Mechanical Engineering 34722 İstanbul, Turkey

${ }^{b}$ Marmara University, Institute of Pure and Applied Sciences, 34722 İstanbul, Turkey

In this study, Inconel 718 material, which is widely used in space aircraft and defense industry and is difficult to be processed by traditional methods, has been cut off with abrasive water-jet. The effects of cutting parameters such as pressure, cutting speed, abrasive consumption and cutting height on kerf have been studied. The input levels needed to be used to obtain the minimum kerf have been determined through Taguchi analysis and the experimental test. The setup of experiment was modelled using linear regression model and an artificial neural network and the results were compared. It was seen that the artificial neural network model gives better results when compared to regression model. The results of experimental test to which the related models were applied are satisfactory.
\end{abstract}

DOI: 10.12693/APhysPolA.129.762

PACS/topics: 07.05.Mh

\section{Introduction}

Cutting by a water jet is based on the processing of the material through chipping off the particles from the material by pressured water at high speed, obtained by increasing its pressure and pushing it through a nozzle [1]. The water jet cutting (WJC) process is carried out by using an abrasive. The wear mechanism is resulting from the impinging effect of the abrasive particles, mixed with the water before releasing the water from the nozzle [2].

In literature, there are a lot of studies about the usage of the water jet for cutting of the materials. However, few studies are present about the improvement of the kerf, which is one of the important factors limiting the use of this method [3].

In this study, the effects of some abrasive WJC variables such as pressure, cutting speed, abrasive consumption and cutting height on the truncated kerf, formed on the Inconel 718 material, have been examined. The minimum and maximum kerf angles measured in the experimental setup were $2.72^{\circ}$ and $5.33^{\circ}$, respectively. Kerf of $2.64^{\circ}$ was obtained through the trials carried out with optimal levels, after the Taguchi analysis [4].

\section{Material and methods}

\subsection{Experimental sample}

In this study Inconel 718 superalloy material with a size of $50 \times 150 \times 2 \mathrm{~mm}^{3}$ has been used. The chemical properties of Inconel 718 superalloy are given in Table I. Hydro-jet HJ3020 model abrasive waterjet machine was used in the experiments (Table II).

* corresponding author; e-mail: muay@marmara.edu.tr
TABLE I

Chemical analysis of Inconel 718 [5].

\begin{tabular}{c|c|c|c|c|c|c|c|c|c|c|c}
\hline \hline & $\mathrm{C}$ & $\mathrm{Si}$ & $\mathrm{P}$ & $\mathrm{Cr}$ & $\mathrm{Ni}$ & $\mathrm{S}$ & $\mathrm{Mo}$ & $\mathrm{Nb}$ & $\mathrm{Ti}$ & $\mathrm{Al}$ & $\mathrm{Fe}$ \\
\hline$[\%]$ & 0.048 & 0.22 & 0.008 & 17.9 & 54.4 & 0.022 & 2.8 & 4.54 & 0.7 & 0.6 & 18.65
\end{tabular}

TABLE II

The variables used in the experiment [5].

\begin{tabular}{c|c}
\hline \hline Pressure $-P[\mathrm{Mpa}]$ & $300,340,380$ \\
\hline Progress speed $-V[\mathrm{~mm} / \mathrm{min}]$ & $60,100,150$ \\
\hline Abrasive consumption $-m[\mathrm{gr} / \mathrm{min}]$ & $100,175,250$ \\
\hline Truncate height $h-[\mathrm{mm}]$ & $2,3,4$ \\
\hline Abrasive $($ sieve $)$ & 120 mesh - Garnet \\
\hline SPL $[\mathrm{mm}] /$ ASPL $[\mathrm{mm}]$ & $0.1 / 1.1$
\end{tabular}

\subsection{Experimental design and measurement}

It is sufficient to make a design with 9 trials according to Taguchi method (L9 table), though 34-81 experiments are needed to be performed in accordance with full matching design of the experiment in this study in which 4 variables with 3 levels have been discussed.

The experimental variables and other important values used in this study, which were held constant, are given in Table II.

The differences between the lower and upper cuts of the material are the indications of the cut kerf and were calculated by Eq. 1,

$$
\theta=\tan ^{-1}\left(\frac{\ddot{u}-a}{2 t}\right) \text {. }
$$

Here $a$ and $\ddot{u}$ values which are the widths of the cut, which have been calculated using $h$ value, which is the distance of the embedding of a steel ball into the cut and $2 r$ is the ball diameter. The kerf and its measurement are shown in Fig. 1.

$$
h=2 r+t-H,
$$




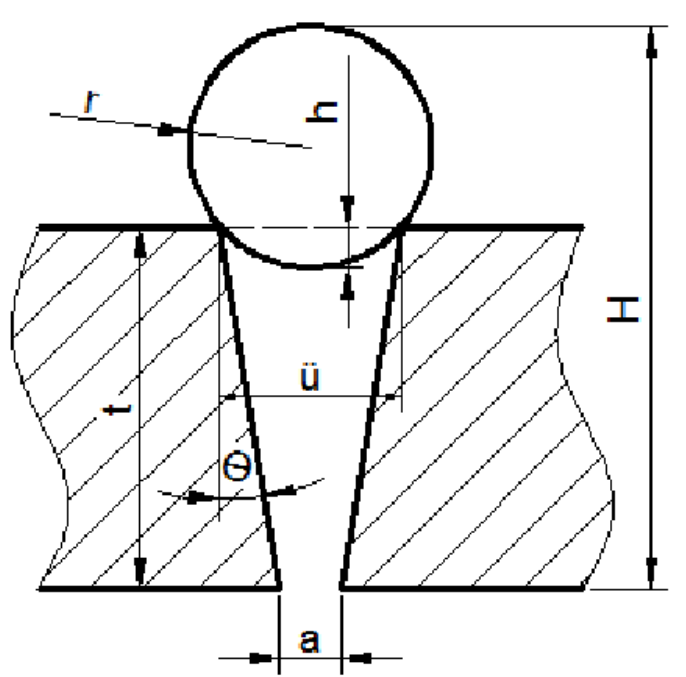

Fig. 1. The kerf and its measurement [5].

$$
l=\left(8 r h-4 h^{2}\right)^{1 / 2} .
$$

The ball diameter is important considering the sensitivity of the measurement device in this method. Each cut has been measured three times at different points and arithmetic mean of them was used.

\subsection{Analysis}

The experimental findings were converted to Taguchi's signal/noise ratio and control experiment was performed determining the optimal levels. The relationship between the variables and artificial neural network (ANN) through regression analysis was modelled and the result of the test and the predictions made according to Taguchi, regression, ANN and average values have been compared.

\section{Results and discussion}

\subsection{Signal/noise ratios and optimal levels}

The results obtained through Taguchi design are converted to signal/noise $(\mathrm{S} / \mathrm{N})$ ratio and expressed in decibels $(\mathrm{dB})$. The signal value represents the actual value, which is provided by system and required to be measured and the noise factor represents the share of undesired factors in this measured value [5]. Since our goal in this study is to reach the minimum kerf value, the equation we used to determine signal/noise ratio is the smallest and the best one $[5,6,7]$.

$$
S / N=10 \log \left(\frac{1}{n} \sum_{i=1}^{n} y_{i}^{2}\right) .
$$

Here $n$ represents the repetition number of experiment in equation, which was four in our study. $y_{i}$ represents the result of the experiment. The $\mathrm{S} / \mathrm{N}$ (signal/noise) ratios of the experimental findings obtained according to this method are given in Table III.

When the optimal levels are identified, the average of $\mathrm{S} / \mathrm{N}$ ratio is calculated separately for the level of each
TABLE III

Experiment results and $\mathrm{S} / \mathrm{N}$ ratios.

\begin{tabular}{c|c|c|c|c|c}
\hline \hline $\mathrm{P}$ & $\mathrm{V}$ & $\mathrm{m}$ & $\mathrm{h}$ & $\theta$ & $\mathrm{S} / \mathrm{N}$ \\
\hline 1 & 1 & 1 & 1 & 3.967 & -11.9699 \\
1 & 2 & 2 & 2 & 4.703 & -13.4483 \\
1 & 3 & 3 & 3 & 3.921 & -11.8671 \\
2 & 1 & 2 & 3 & 4.036 & -12.1184 \\
2 & 2 & 3 & 1 & 3.324 & -10.4326 \\
2 & 3 & 1 & 2 & 5.147 & -14.2313 \\
3 & 1 & 3 & 2 & 2.720 & -8.6916 \\
3 & 2 & 1 & 3 & 5.331 & -14.5366 \\
3 & 3 & 2 & 1 & 4.096 & -12.2480
\end{tabular}

variable. The biggest $\mathrm{S} / \mathrm{N}$ ratio among the values obtained is identified as the optimal level for the related variable. The calculation results obtained according to $\mathrm{S} / \mathrm{N}$ ratios are given in Table IV and their graphical representation is given in Fig. 2.

TABLE IV

$\mathrm{S} / \mathrm{N}$ ratios of variable levels.

\begin{tabular}{c|c|c|c|c}
\hline \hline Level & $P$ & $V$ & $m$ & $h$ \\
\hline 1 & -12.43 & -10.93 & -13.58 & -11.55 \\
2 & -12.26 & -12.81 & -12.60 & -12.12 \\
3 & -11.82 & -12.78 & -10.33 & -12.84 \\
Maximum Difference & 0.6 & 1.88 & 3.25 & 1.29 \\
Order of Importance & 4 & 2 & 1 & 3
\end{tabular}

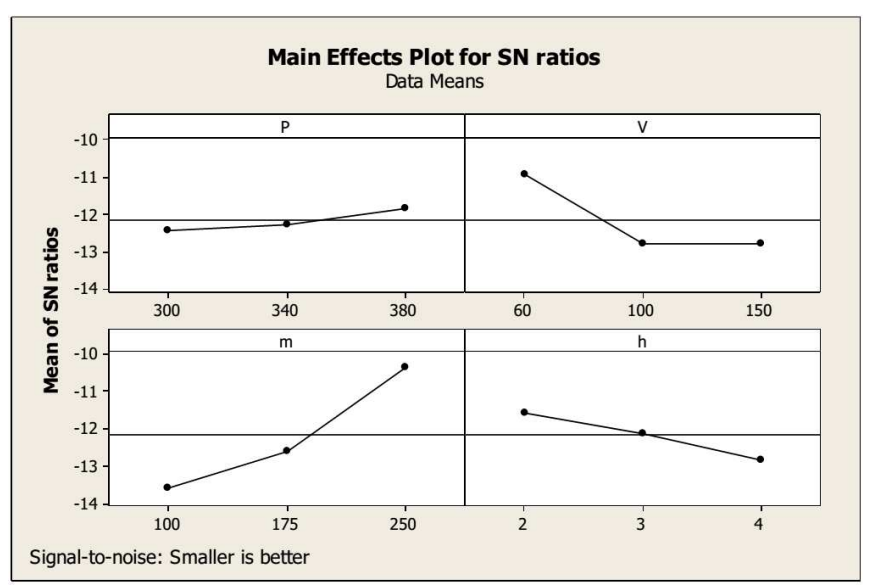

Fig. 2. The effect of variables on kerf $(\mathrm{S} / \mathrm{N})[5]$.

According to Taguchi analysis, as seen in Table IV and Fig. 2, the minimum kerf value is obtained when the values of pressure and abrasive material consumption are maximum (P3-m3) and the values of cutting speed and cutting height are minimum $(V 1-h 1)$.

The value obtained as the result of the control experiment, performed using the optimal values was determined to be $2.64^{\circ}$. 


\section{TABLE V}

The most appropriate levels for a minimum kerf [5].

\begin{tabular}{c|c|c|c|c|c}
\hline \hline \multicolumn{5}{|c|}{ The most appropriate levels } & \\
\hline Variable & $\mathrm{P}$ & $\mathrm{V}$ & $\mathrm{m}$ & $\mathrm{h}$ & \multirow{2}{*}{ Kerf } \\
\hline Level & 3 & 1 & 3 & 1 & \\
Value _ Unit & $380 \mathrm{Mpa}$ & $60 \mathrm{~mm} / \mathrm{min}$ & $250 \mathrm{gr} / \mathrm{min}$ & $2 \mathrm{~mm}$ & $2.64^{0}$
\end{tabular}

\subsection{Regression analysis}

It is the mathematical expression of the correlation which is based on the least squares method, as $y=a+b x$, etc. The assessment of the curve can be made using the mean square error (MSE), the sum of the squares of errors used in evaluation.

$$
M S E=\frac{1}{n} \sum_{i=1}^{n}\left(g_{i}-t_{i}\right)^{2} .
$$

Here $g_{i}$ are the real values, $t_{i}$ are the predicted values and $n$ is the number of data points.

The smaller the MSE, the smaller are the errors. On the other hand, it is not a preferred approach because this term is dependent on the size. Therefore, index $r^{2}$ is more commonly used [8].

Our hypothesis established for analysis are as follows:

Null hypothesis (H0): "There is no linear relationship between the variables and the kerf".

Research Hypothesis (H1): "There is a linear relationship between the variables and the kerf".

According to the regression analysis results, (Table VI) there is a positive correlation between cut kerf and cutting speed, cutting height and a negative correlation between pressure and abrasive consumption. However these correlations are not meaningful statistically in terms of pressure and cutting height $(>0.1)$. Hypothesis $\mathrm{HO}$ is rejected in terms of cutting speed and abrasive consumption.

TABLE VI

Coefficients.

\begin{tabular}{c|c|c|c|c}
\hline \hline Predictor & Coef & SE Coef & T & P \\
\hline Constant & 4.66907 & 1.56731 & 2.97903 & 0.041 \\
P & -0.00185 & 0.00407 & -0.45399 & 0.673 \\
V & 0.00862 & 0.00361 & 2.38591 & 0.076 \\
m & -0.00996 & 0.00217 & -4.58593 & 0.01 \\
h & 0.31669 & 0.16286 & 1.94453 & 0.124
\end{tabular}

$$
S=0.398929 R-S q=88.48 \% R-S q(\operatorname{adj})=76.95 \%
$$

$$
\begin{aligned}
& K \operatorname{erf}=4.67-0.00185 P+0.00862 \mathrm{~V} \\
& \quad-0.00996 m+0.317 h .
\end{aligned}
$$

The pie chart created, based on the results of epsilon squared, calculated to get an idea about the practical importance of effect is given in Fig. 3 .

\section{Epsilon Squared}

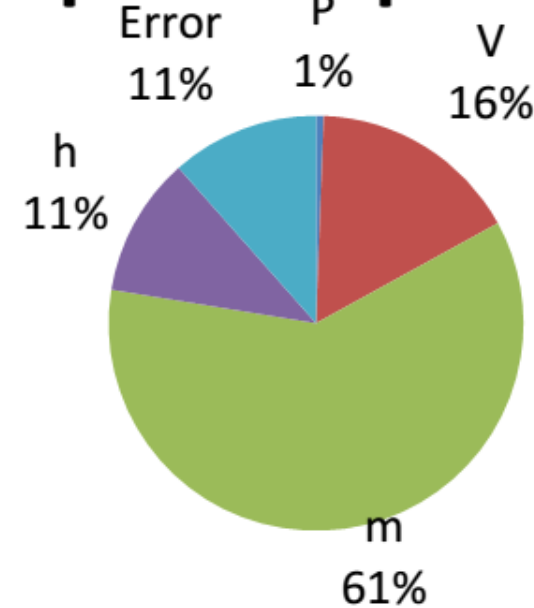

Fig. 3. Epsilon squared [5].

\subsection{Artificial neural network}

Artificial neural networks, are the computer systems developed with the aim of accomplishing some abilities such as acquiring, creating and exploring new information, which are some of the characteristics of the human brain, automatically, through learning and without getting any help [9].

The best and fast learning algorithm type in the artificial neural network is Levenberg-Marquadtr (LM) [10]. Although training in the LM algorithm uses a lot of memory, it reaches conclusion in a shorter time [11].

The activation functions used mostly between the layers of the neural networks are tangent, sigmoid, logarithmic sigmoid and purelin.
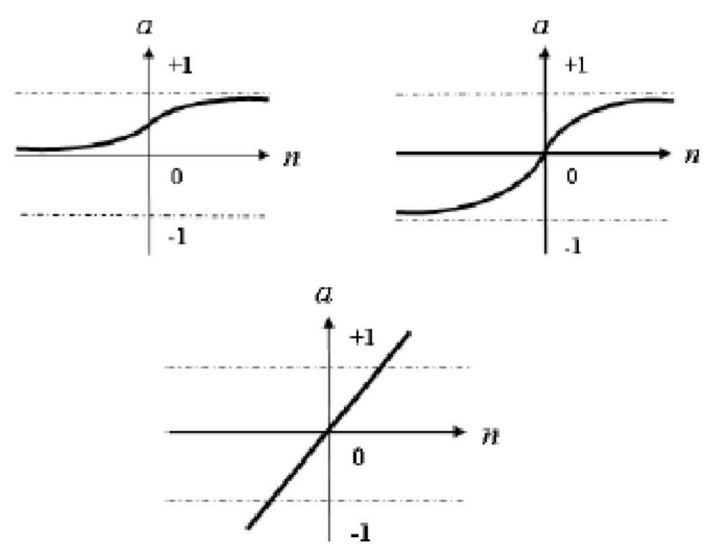

Fig. 4. Tangent-sigmoid, logarithmic-sigmoid and purelin functions respectively (input-output) [12].

Tan-sigmoid transfer function provides a smooth transition and purelin provides a sharp transition as can be seen in Fig. 4. 
Input parameters for the ANN model are pressure $P$, progressing speed $V$, abrasive consumption $m$, cutting height $h$, out parameter and kerf $e$. Matlab R2007a software was used for training and testing of ANN.

Twenty training approaches have been carried out, using two transfer functions such as hyperbolic tangent sigmoid (tansig) and logarithmic sigmoid (logsig) and ten different neuron numbers $(4,5,6,7,8,9,10,15,20,25)$ in the hidden layer, to determine the structure by which the best results could be obtained. Max-epoch value of 300 has been selected in training and the best prediction value of the optimum experiment result has been reached using the tansig function with eight neurons in the hidden layer.

\subsection{Comparison of $A N N$ and regression designs}

When Fig. 5 and Table VII are examined, it is seen that the ANN results are closer to the experimental data.

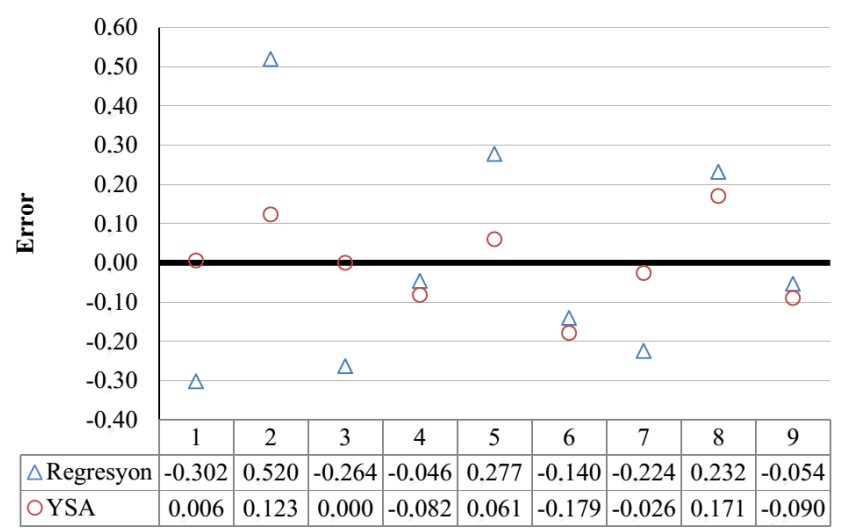

Fig. 5. The distance between the estimates and experimental data.

\section{TABLE VII}

Statistical values of the models [5].

\begin{tabular}{c|c|c|c}
\hline \hline Experiment & Experiment & Regression & YSA tansig-8 \\
\hline $\mathrm{N}$ & 9 & 9 & 9 \\
$\mathrm{R}^{2}$ & 1.0000 & 0.8848 & 0.9827 \\
Adj R & 1.0000 & 0.7695 & 0.9655 \\
$\mathrm{MSE}$ & 0.0000 & 0.0707 & 0.0106 \\
Correlation & 1.0000 & 0.9406 & 0.9913
\end{tabular}

\subsection{Comparison of optimization predictions}

The prediction value is calculated by considering signal/noise ratios with the equation given below.

$$
\begin{aligned}
\eta & =\eta_{m}+\left(\eta_{P 3}-\eta_{m}\right)+\left(\eta_{V 1}-\eta_{m}\right) \\
& +\left(\eta_{m 3}-\eta_{m}\right)+\left(\eta_{h 1}-\eta_{m}\right) .
\end{aligned}
$$

In this equation, $\eta_{m}$ represents the arithmetic mean of the $\mathrm{S} / \mathrm{N}$ values, $\eta_{P 3}$ represents the arithmetic mean of the
$\mathrm{S} / \mathrm{N}$ values, corresponding to the $3^{r d}$ level of the $P$ variable [5-7]. Since the result obtained through this equation would be $\mathrm{S} / \mathrm{N}$ value, it is converted to raw value substituted into Eq. 2. The prediction of the average value is also performed using the arithmetic mean of raw values instead of $\mathrm{S} / \mathrm{N}$ values in this equation. The estimations and the result of control experiment are given in Table VIII.

TABLE VIII

Comparison of results of the prediction.

\begin{tabular}{c|c|c|c|c|c}
\hline \hline & Exp. & Taguchi S/N & Mean & Regression & YSA \\
\hline$P 3-V 1-m 3-h 1$ & 2.6394 & 2.5463 & 2.3257 & 2.6277 & 2.6499 \\
\% Difference & $0.00 \%$ & $3.53 \%$ & $11.89 \%$ & $0.44 \%$ & $-0.40 \%$
\end{tabular}

The best predictions of the experimental results have been obtained through YSA and regression equations. Since various prediction values are close to the real values and real value results gave the minimum kerf, it is proved that successful results have been obtained through Taguchi design.

\section{Conclusion}

The regression model and the obtained average effect indicate that the cut kerf is inversely proportional to abrasive consumption and pressure and directly proportional to cutting speed and cutting height. Since the effects of pressure and cutting height on the kerf have not been evaluated to be statistically meaningful within the experimental conditions, abrasive consumption and cutting speed have been determined as the most effective factors for the kerf. In other studies, where different materials were cut, it is observed that the kerf decreases, when the abrasive consumption increases [12-14] and the kerf increases when cutting speed and cutting height increase [3, 13-17].

In similar studies, the pressure should be selected in a wider range and the effects of abrasive size on the truncated kerf should be investigated. In our study the smallest kerf value obtained through experimental test was $2.64^{\circ}$ and the largest kerf value was $5.33^{\circ}$.

\section{References}

[1] N. Geren, T. Tunç, Mühendis Ve Makine Dergisi 42, 500 (2001).

[2] M.K. Külekçi, A. Akkurt, Niğde Üniversitesi Mühendislik Bilimleri Dergisi 5, 13 (2001).

[3] G. Aydın, İ. Karakurt, K. Aydıner, Madencilik 49, 17 (2010).

[4] S. Mezarcıöz, R.T. Oğulata, Tekstil Ve Konfeksiyon, 4 (2010).

[5] I. Ay, Süper Alaşımların Aşındırıcılı Sujeti İle İslenebilirliğinin Araştırılması, Marmara University, Master Thesis, 2010.

[6] R.R. Kanjit, A Primer on the Taguchi Method Cover, Van Nostrand Reinhold, New York (1990). 
[7] N. Sakarya, C.Göloğlu, Gazi Üniv. Müh. Mim. Fak. Der. 21, 603 (2006).

[8] M. Sönmez, Sayısal Analiz Ders Notları, Aksaray Üniversitesi İnşaat Mühendisliği Bölümü, 2008.

[9] M. Demetgül, O. Yazıcıŏlu,, Teknoloji 9, 101 (2006).

[10] H.S. Ergür, Eskişehir Osmangazi Üniversitesi Mühendislik Mimarlık Fakültesi Dergisi XXII, 2 (2009).

[11] M.H.Sazlı, H.Tanrıkulu, XII. Türkiye'de Internet Konferansı 8-10 Kasım 2007 Bildiriler Kitabı, Ankara, 2007, p. 217.

[12] J.J.R. Jegaraj, N.R. Babu, Int. J. Mach. Tool. Manu. 45, 1443 (2005).
[13] D.K. Shanmugam, S.H. Masood, J. Mater. Process. Techn. 209, 3887 (2009).

[14] J. Wang, W.C.K. Wong, Int. J. Mach. Tool. Manu. 39, 855 (1999).

[15] V. Gupta, P.M. Pandey, M.P. Garg, R. Khanna, N.K. Batra, Procedia Mater. Sci. 6, 140 (2014).

[16] M. Ay, U. Çaydaş, A. Hasçalık, Mater. Manuf. Process. 25, 1160 (2010).

[17] A. Haşçalik, U. Çaydaş, H. Gürün, Material. Design 28, 1953 (2007). 